\title{
Analytical validity of DecisionDx-SCC, a gene expression profile test to identify risk of metastasis in cutaneous squamous cell carcinoma (SCC) patients
}

\section{Sherri Borman}

Castle Biosciences Inc

Jeff Wilkinson

Castle Biosciences Inc

\section{Lauren Meldi-Sholl}

Castle Biosciences Inc

Clare Johnson

Castle Biosciences Inc

Kelsey Carter

Castle Biosciences Inc

Kyle R. Covington

Castle Biosciences Inc

Alison Fitzgerald

Castle Biosciences Inc

Sarah J. Kurley

Castle Biosciences Inc

Aaron S. Farberg

Castle Biosciences Inc

Matthew S. Goldberg

Castle Biosciences Inc

Federico A. Monzon

Castle Biosciences Inc

Kristen Oelschlager

Castle Biosciences Inc

Robert W. Cook ( $\nabla$ rcook@castlebiosciences.com )

Castle Biosciences Inc https://orcid.org/0000-0003-1166-4796

\section{Research}

Keywords: Gene expression profiling, DecisionDx-SCC, cutaneous squamous cell carcinoma, metastasis, analytic validity

Posted Date: November 1st, 2021

DOI: https://doi.org/10.21203/rs.3.rs-994742/v1 
License: @ (1) This work is licensed under a Creative Commons Attribution 4.0 International License. Read Full License

Version of Record: A version of this preprint was published at Diagnostic Pathology on February 25th, 2022. See the published version at https://doi.org/10.1186/s13000-022-01211-w. 


\section{Abstract \\ Background}

To improve identification of patients with cutaneous squamous cell carcinoma (SCC) at high risk for metastatic disease, the DecisionDx-SCC assay, a prognostic 40-gene expression profile (40-GEP) test, was developed and validated. The 40-GEP assay utilizes RT-PCR gene expression analysis on primary tumor biopsy tissue to evaluate the expression of 34 signature gene targets and 6 normalization genes. The test provides classifications of low risk (Class 1), moderate risk (Class 2A), and high risk (Class 2B) of metastasis within 3 years of diagnosis. The primary objective of this study was to validate the analytical performance of the 40 gene expression signature.

\section{Methods}

The repeatability and reproducibility of the 40-GEP test was evaluated by performance of inter-assay, intra-assay, and inter-operator precision experiments along with monitoring the reliability of sample and reagent stability for class call concordance. The technical performance of clinical orders from September 2020 through July 2021 for the 40-GEP test was assessed.

\section{Results}

Patient hematoxylin and eosin (H\&E) stained slides were reviewed by a board-certified pathologist to assess minimum acceptable tumor content. Class specific controls (Class 1 and Class 2B) were evaluated with Levey Jennings analysis and demonstrated consistent and reproducible results. Inter-assay, inter-operator and intra-assay concordance were all $\geq 90 \%$, with short-term and long-term RNA stability also meeting minimum concordance requirements. Of the 2,446 orders received, $93.4 \%$ remained eligible for testing, with $96.8 \%$ of all tested samples that completed the assay demonstrating actionable class call results.

\section{Conclusion}

DecisionDx-SCC demonstrates a high degree of analytical precision, yielding high concordance rates across multiple performance experiments, along with exhibiting robust technical reliability on clinical samples.

\section{Background}

Although prognosis of cutaneous squamous cell carcinoma (SCC) is generally favorable, an estimated $6 \%$ of the greater than 1,000,000 cases diagnosed annually develop regional or distant metastasis, with approximately $2 \%$ dying from this disease $(1-3)$. With the striking increase in incidence over the past 30 years (4), SCC continues to be an increasing burden on the healthcare system. The subset of SCC patients that carry an elevated risk of metastasis and death are termed 'high risk.' Current National Comprehensive Cancer Network (NCCN) guidelines (5) recommend treatment strategies based on broad criteria for identifying a high-risk SCC patient (those with a single clinicopathologic risk factor); unfortunately, this approach has led to inconsistent patient management decisions (68). Tumor staging systems also are solely based on clinicopathologic factors for risk assessment, resulting in low positive predictive values (meaning many high-risk SCC patients do not progress to advanced disease) (9). Therefore, improvement in the prediction of metastatic risk is crucial for early identification of poor outcomes and can greatly assist with the unmet clinical need of establishing more risk-appropriate patient management. 
A prognostic 40-gene expression profile (40-GEP) test, clinically available as DecisionDx-SCC, has been developed and validated to show improved stratification of metastatic risk in high-risk SCC patients compared to current staging systems alone (9). A neural network-based predictive algorithm based upon the normalized gene expression values of 34 discriminant genes was used to predict classification of metastatic tumor biology risk, along with 6 additional genes chosen as controls (9), resulting in a 40-gene expression profile. The 40-GEP assay has been clinically validated and classifies SCC tumors into low (Class 1), moderate (Class 2A), and high (Class 2B) risk groups for regional or distant metastasis within 3 years of diagnosis. Clinical utility studies have also supported the integration of the 40GEP test with standard guidelines for a more refined risk-appropriate SCC patient management (10-13).

This study outlines the analytical validation of the 40-GEP test, including reproducibility data (inter-and intra-assay reliability and inter-operator precision), repeatability, stability, and technical experience of clinical testing in accordance with published guidelines $(14,15)$. The analysis was developed and performed in a CAP-accredited, New York StateApproved, CLIA-certified high throughput, molecular laboratory with high quality, standard operating procedures (SOPs).

\section{Methods}

\section{Sample and clinical data collection}

Samples were collected under a protocol that was reviewed and approved by the appropriate Institutional Review Board (IRB) for each contributing institution. Laboratory personnel were blinded to clinical truth outcomes (e.g., metastasis). The 40-GEP assay is intended for use with RNA obtained from formalin-fixed, paraffin embedded (FFPE) tissue from the biopsy of primary invasive SCC tumors with one or more clinicopathologic risk factors. Ten $5 \mu \mathrm{m}$ thick tissues sections were cut from FFPE blocks containing the biopsied tissue. The first slide was stained with hematoxylin and eosin (H\&E) and sent to Castle Biosciences' centralized laboratory along with the nine subsequent unstained slides.

\section{RT-PCR preparation}

FFPE samples were processed, as previously described $(9,16)$. An area representative of the tumor was identified on the H\&E slide by a dermatopathologist. The corresponding area was then manually macro-dissected from the unstained tissue slides and pooled into a single tube by trained, molecular technologists. The clinically allowable minimum for testing is $\geq 40 \%$ tumor nuclei $(9,16)$. The RNA is extracted from the FFPE samples using the QiaSymphony auto-nucleic acid extractors (Qiagen) and quantified. The isolated RNA from the samples were split into separate tubes (to be run concurrently) and followed by reverse transcription to cDNA using the High-Capacity cDNA Reverse Transcription Kit (Applied Biosciences). After a 14-cycle pre-amplification with a custom OpenArray PreAmp pooled assay (ThermoFisher Scientific) and dilution, the OpenArray chip (Applied Biosystems) was loaded using the QuantStudio 12K Flex Accufill system (Applied Biosystems) and high throughput qPCR was performed using the QuantStudio 12K Flex PCR system (Applied Biosystems). Resulting qPCR data were normalized to internal control genes for data analysis. All assay runs and sample results underwent a multifactorial quality control (QC) review process, including assessment of the number of amplified probes within each sample. A specimen was reported as a multiple gene failure (MGF) if more than 3 target genes failed to amplify across the panel.

\section{Risk assignment}

The expression of 6 "housekeeping" genes are utilized to normalize the expression of the 34 discriminant genes. The controls were chosen based on their robust expression and low variance (9). The result is expressed as a $\Delta \mathrm{Ct}$ (the difference in expression level between the test gene and internal controls). The sample's raw expression data is then 
subject to a proprietary algorithm comprised of two gene signatures (neural networks), both established and locked following development with a training set of SCCs with known outcomes (9). The algorithm returns two quantitative linear probability scores from 0 to 1.0 (Signature 1 and Signature 2). A sample is run in duplicate, and the values of each signature are averaged, resulting in a qualitative classification of 3 possible risk groups: Class 1 (low risk), Class 2A (moderate risk) or Class 2B (high risk) tumor biology (Fig. 1).

\section{Class Call Concordance Determination}

Analytic validity and reliability are reported as the qualitative concordance of class assignment and the correlation of quantitative probability score values. Class call concordance was evaluated in the three reported risk groups: Class 1, Class $2 \mathrm{~A}$ and Class 2B. To be deemed acceptable the class calls between the original run and subsequent runs had to be $>90 \%$.

\section{Results}

\section{RNA input quantity and tumor content}

H\&E-stained slides for each specimen tested were reviewed by a board-certified pathologist to assess for both the amount of tumor tissue and the appropriate area to be macro-dissected. The minimum tumor content from a patient's sample deemed acceptable was previously established at $\geq 40 \%(9,16)$. Following the pathologist evaluation, samples were submitted to the laboratory where RNA from 10 samples with known concentrations were serially diluted down from $10 \mathrm{ng} / \mu \mathrm{l}$ to $1.25 \mathrm{ng} / \mu \mathrm{l}$ (Fig. 2). A dilution series was performed to establish minimum RNA inputs for the assay. On the basis of MGF rate, $5 \mathrm{ng} / \mu \mathrm{l}$ was determined to be the lower input limit for RNA concentration.

\section{Repeatability-Assay robustness}

Control processes were implemented to ensure the accuracy and precision of the 40-GEP assay for clinical testing. Positive and negative controls are included with every batch of clinical samples, in addition to no template water controls and a qPCR DNase control to assess potential DNA contamination. The reproducibility of the assay performance was monitored with well-characterized, previously run, positive controls (Class 1 and Class 2B) to ensure all experiments described in the validation performed within clinically acceptable confidence limits $( \pm 2$ standard deviation [SD]). The performance of the control's mean probability scores was evaluated with Levey Jennings analysis to illustrate the stability and assay robustness across multiple runs (Fig. 3). Class 1, Signature 1 controls had a mean probability score of 0.00053 and a standard deviation (SD) of 0.00003 with a range of $0.00047-0.00063$. Class 1 , Signature 2 controls had a mean probability score of 0.042018 and a SD of 0.000009 with a range of $0.042004-0.042048$. Class 2B, Signature 1 controls had a mean probability score of 0.883023 and a SD 0.014953 with a range of $0.806996-0.904568$. Class $2 B$, Signature 2 controls had a mean probability score of 0.941408 and a SD of 0.000510 with a range of $0.936554-0.941503$. These control samples were included from experiment to experiment and across multiple reagent lots. No assay was rejected due to amplification of a negative control or a failed positive control probability score. The control limits $(\mathrm{CL})$, measured as the mean quantitative probability scores, upper control limit (UCL) and lower control limit (LCL) were also established by Levey-Jennings analysis. The Class 1 , Signature 1 positive control sample had a CL of 0.0005 , UCL of 0.007 , and LCL of 0.004 . The Class 1 , Signature 2 positive control sample had a CL of 0.0420 , UCL of 0.0421 , and LCL of 0.0420 . The Class $2 B$, Signature 1 positive control sample had a CL of 0.8830 , UCL of 0.9281 , and LCL of 0.8379 . Lastly, the Class $2 \mathrm{~B}$, Signature 2 positive control sample had a CL of 0.9415 , UCL of 0.9416 , and LCL of 0.9414 . These data support the robustness of the assay and reflect its ability to consistently perform to expectations. 
To assess the inter-assay reliability of the 40-GEP test, a precision experiment was performed by running 30 samples in duplicate $(1 \& 2)$ for the original run, with a subsequent run prepared in duplicate $(3 \& 4)$ on a different day with a different instrument and analyst (Table 1). Controls were included for each run. The class calls resulting from the average probability scores of both the Signature 1 and Signature 2 components of the algorithm were evaluated, followed by determination of class assignment concordance. One sample was removed due to dilution error resulting for a total of 29 evaluable samples. Following class call analysis, 27/29 (93\%) samples were determined to be concordant for the class call assignment. Of the two cases that changed class call, one class call change was from Class 2A to Class 1 and the other was from Class 2A to Class 2B. The bias analysis (mean absolute difference) in matched probability scores was -0.04 for Signature 1 and 0.02 for Signature 2, demonstrating that the variability was within normal allowable clinical variation and not likely to change class assignment.

Inter-operator precision was also assessed during the inter-assay experiment and was determined by the evaluation of 20 samples with two different operators on separate days on two different machines. Inter-machine precision was evaluated by use of the same 20 samples by the same two operators on two different QuantStudio 12k Flex machines (ThermoFisher) on different days. The class call concordance was considered acceptable with 19/20 (95\%) samples determined to be concordant (data on file).

For the DecisionDx-SCC intra-assay precision experiment, 46 FFPE samples were assayed (Table 2) with each sample run in duplicate (for a total of 4 replicates) by the same technologist for an open array (5 samples per array, with 10 arrays on a single instrument over 2 days) from one RNA extraction event of sample preparation. The class calls resulting from the average probability scores for both the Signature 1 and Signature 2 components of the algorithm of replicates $1 \& 2$ were compared to the class calls resulting from the average probability scores for both the Signature 1 and Signature 2 components of the algorithm for replicates $3 \& 4$. To be considered acceptable, the concordance needed to be $\geq 90 \%$ for class call. Following class call analysis, samples were concordant for class call assignment in 45/46 (98\%) samples. The single case changing from Class 1 to Class $2 A$ generated probability scores within 0.01 for the Signature 2 cut point $(<0.05)$, a difference that is within the SD of the reproducibility curves and expected clinical variability curves. The bias analysis in matched probability scores was -0.03 for Signature $1 \& 0.005$ for Signature 2 , showing variability to be within acceptable clinical variation and not likely to change class assignment.

\section{Specimen and reagent stability}

To assess RNA stability and longevity following long-term storage at $-80^{\circ} \mathrm{C}, 23 \mathrm{FFPE}$ samples were tested over a span of 146 days across multiple different runs (Table 3). The class call concordance was 22/23 (96\%) samples. To evaluate sample stability, specimens were assessed following uninterrupted processing of the assay versus following short-term storage. For short-term storage, the cDNA was held following reverse transcription (RT) $(n=15)$ at $4^{\circ} \mathrm{C}$ for 96 hours, then continuing through with the entire assay. The samples were run on a single open array with the same operator. The performance metrics and concordance analyses were deemed acceptable.

Lot-to-lot reproducibility for critical reagents was evaluated using between 5-11 samples over timespans ranging from 3 months (for assay reagents) to 11 months (for RNA extraction reagents), utilizing 2 to 3 different lots. Summary data from Table 3 illustrates a 90\%-100\% class call concordance for all reagents: extraction reagents (9/10; 90\%), RT Kit \& RNase reagents $(10 / 11 ; 91 \%)$, pooled assay \& pre-amplification master mix reagents $(5 / 5 ; 100 \%)$ and open array (OA) \& open array master mix (OA MM) reagents (8/8; 100\%). This class call analysis of the individual sample data from lot-to-lot shows consistent reproducibility. 


\section{DecisionDx-SCC technical experience}

Over an 11-month time span, September 1, 2020, through July 31, 2021, 2,586 eligible clinical orders for the 40-GEP test were received from across the United States (Fig 4). Of these, 86 (3.3\%) and 84 (3.2\%) samples were rejected due to QC failure (having an insufficient tumor content of $<40 \%$ ) or "quantity not sufficient" (QNS; RNA $<5.0 \mathrm{ng} / \mu \mathrm{l}$ ), respectively. Overall, 2,345 (97.1\%) of all tested samples gave successful, actionable class call outcomes (Class 1: 1,626 (69.3\%) samples, Class 2A: 656 (28.0\%) samples, and Class 2B: 63 (2.7\%) samples). The remaining 71 (2.9\%) samples tested were reported as a MGF as the final result. The average turn-around time from receipt of tissue to report distribution was less than 5 days.

\section{Discussion}

Effective molecular prognostic assays are becoming more predominant for clinical decision making of oncology patients. Due to this rapidly evolving field, it has become critical to provide reproducible and reliable risk assessment via analytical and clinical validity, along with demonstrations of its added value to patient management decisions, defined as clinical utility (17). Clinical validity and utility studies regarding the 40-GEP test not only support its ability to improve upon current methods of predicting a tumor's metastatic risk, but also that physicians would appropriately integrate test results into patient management decisions $(10,11)$. Here, we report the analytic validity of the assay by using accepted methods for reproducibility and technical reliability of clinical testing in accordance with published guidelines $(14,15)$.

Determination of minimum suitable RNA concentration necessary for accurate reproducibility of class call assignments is of the utmost importance. These data were achieved by following a comprehensive protocol previously published $(9,16)$. Also, validation of the repeatability of the assay was shown using the Levey-Jennings quality control analysis which exhibited stringent upper and lower control limits. These robust results highlight the proficiency of the procedures used to perform the 40-GEP test in a centralized CLIA-certified, CAP-accredited and New York State-approved laboratory.

The 40-GEP test is the first gene expression profile test for cutaneous squamous cell carcinoma. Thus, while the analytic framework for this type of test has been ascertained (16), the qualitative classification system of three possible risk groups is novel. The definitive precision of the assay when making class call assignments can be seen in the inter-assay reliability results demonstrating $93 \%$ of samples concordant for class call, inter-operator precision demonstrating $95 \%$ concordance, and intra-assay reliability having $98 \%$ class call concordance. This confidence was also evident with the acceptable concordance of sample stability following long-term storage of RNA and short-term storage of cDNA following RT hold. Additionally, being that quality assurance for laboratory reagents are required as part of assay performance verification (18) we executed lot-to-lot reproducibility experiments for critical reagents with results meeting or exceeding the requirements for a clinically applied prognostic test (18).

Finally, an indication of the consistent high performance of the 40-GEP can be seen by its technical success rate. Over an 11-month timeframe, 2,586 40-GEP tests were ordered, of which $93.5 \%$ were eligible to be run on the assay. Of these tests, $97.1 \%$ were successful in giving valid class calls. The results provided by the 40-GEP may help curb the dramatic increase seen in mortality of SCC patients after loss of locoregional control of disease by providing a patient with their risk of nodal or distant metastases early in the disease state and informing appropriate management decisions based on risk.

\section{Conclusion}


Following published guidelines for establishing analytic validity, the results of this study substantiate the accuracy and reliability of the DecisionDx-SCC test regarding its robust repeatability and reproducibility. The variability in sample and reagent stability was minimal, demonstrating the value of implementing the rigorous protocols used to perform the assay. The notable technical performance of the test also validated its strength as a robust clinical assay. In summary, this data, along with clinical validity and utility studies, show that the 40-GEP test can add value to highrisk SCC patient risk assessment with the potential to improve disease related outcomes.

\section{Abbreviations}

40-GEP

40-gene expression profile

CL

control limits

FFPE

formalin-fixed, paraffin embedded

$H \& E$

hematoxylin and eosin

IRB

Institutional Review Board

LCL

lower control limit

MGF

multiple gene failure

NCCN

National Comprehensive Cancer Network

$\mathrm{OA}$

open array

OA MM

open array master mix

QC

quality control

RT

reverse transcription

SCC

cutaneous squamous cell carcinoma

SD

standard deviation

SOP

standard operating procedure

UCL

upper control limit

\section{Declarations}

- Ethics approval and consent to participate- N/A 
- Consent for publication- N/A

- Availability of data and materials- Relevant data generated or analyzed during this study are included in this published article (and its supplementary information files). Additional data analyzed during the current study are available from the corresponding author on reasonable request.

- Competing interests- Authors are/have been employees of Castle Biosciences, Inc. and hold stock in the company.

- Funding-This study was sponsored by Castle Biosciences, Inc.

- Authors' contributions- Data acquisition, data analysis, sample processing, manuscript development and editing: SB; data acquisition, data analysis, sample processing: JW, LM-S; data acquisition: CJ, KC; data analysis, data interpretation and contributing to manuscript development: KRC, SJK; data interpretation and contributing to manuscript development: FA, KO, RWC; data interpretation, contributing to manuscript development, writing and editing: ALF, ASF, MSG

- Acknowledgements- N/A

- Authors' information (optional)- N/A

\section{References}

1. Que SKT, Zwald FO, Schmults CD. Cutaneous squamous cell carcinoma: Incidence, risk factors, diagnosis, and staging. J Am Acad Dermatol. 2018 Feb;78(2):237-47.

2. Karia PS, Han J, Schmults CD. Cutaneous squamous cell carcinoma: Estimated incidence of disease, nodal metastasis, and deaths from disease in the United States, 2012. J Am Acad Dermatol. 2013 Jun 1;68(6):957-66.

3. Rogers HW, Weinstock MA, Feldman SR, Coldiron BM. Incidence Estimate of Nonmelanoma Skin Cancer (Keratinocyte Carcinomas) in the US Population, 2012. JAMA Dermatol. 2015 Oct 1;151(10):1081.

4. Waldman A, Schmults C. Cutaneous Squamous Cell Carcinoma. Hematology/Oncology Clinics of North America. 2019 Feb;33(1):1-12.

5. National Comprehensive Cancer Network. Squamous Cell Skin Cancer, NCCN Guidelines Version 2.2021, in NCCN Clinical Practice Guidelines in Oncology. [Internet]. 2021 [cited 2021 Sep 9]. Available from: https://www.nccn.org/professionals/physician_gls/pdf/squamous.pdf

6. Jambusaria-Pahlajani A, Hess SD, Katz KA, Berg D, Schmults CD. Uncertainty in the Perioperative Management of High-Risk Cutaneous Squamous Cell Carcinoma Among Mohs Surgeons. Archives of Dermatology. 2010 Nov 1;146(11):1225-31.

7. Ross AS, Schmults CD. Sentinel lymph node biopsy in cutaneous squamous cell carcinoma: a systematic review of the English literature. Dermatol Surg. 2006 Nov;32(11):1309-21.

8. Jambusaria-Pahlajani A, Miller CJ, Quon H, Smith N, Klein RQ, Schmults CD. Surgical Monotherapy Versus Surgery Plus Adjuvant Radiotherapy in High-Risk Cutaneous Squamous Cell Carcinoma: A Systematic Review of Outcomes. Dermatologic Surgery. 2009 Apr;35(4):574-84.

9. Wysong A, Newman JG, Covington KR, Kurley SJ, Ibrahim SF, Farberg AS, et al. Validation of a 40-gene expression profile test to predict metastatic risk in localized high-risk cutaneous squamous cell carcinoma. J Am Acad Dermatol. 2021 Feb;84(2):361-9. 
10. Litchman GH, Fitzgerald AL, Kurley SJ, Cook RW, Rigel DS. Impact of a prognostic 40-gene expression profiling test on clinical management decisions for high-risk cutaneous squamous cell carcinoma. Curr Med Res Opin. 2020 May 18;1-6.

11. Farberg AS, Hall MA, Douglas L, Covington KR, Kurley SJ, Cook RW, et al. Integrating gene expression profiling into NCCN high-risk cutaneous squamous cell carcinoma management recommendations: impact on patient management. Curr Med Res Opin. 2020 May 18;1-7.

12. Teplitz R, Giselle P, Litchman GH, Rigel DS. Impact of Gene Expression Profile Testing on the Management of Squamous Cell Carcinoma by Dermatologists. J Drugs Dermatol. 2019 Oct 1;18(10):980-4.

13. Arron ST, Blalock TW, Guenther JM, Hyams DM, Ibrahim SF, Koyfman SA, et al. Clinical Considerations for Integrating Gene Expression Profiling into Cutaneous Squamous Cell Carcinoma Management. J Drugs Dermatol. 2021 Jun 1;20(6):5s-s11.

14. Sun F, Bruening W, Uhl S, Ballard R, Tipton K, Schoelles K. Quality, Regulation and Clinical Utility of Laboratorydeveloped Molecular Tests. In: Quality, Regulation and Clinical Utility of Laboratory-developed Molecular Tests. Rockville (MD); 2010. (AHRQ Technology Assessments).

15. Engstrom PF, Bloom MG, Demetri GD, Febbo PG, Goeckeler W, Ladanyi M, et al. NCCN molecular testing white paper: effectiveness, efficiency, and reimbursement. Journal of the National Comprehensive Cancer Network: JNCCN. 2011 Dec;9 Suppl 6:S1-16.

16. Cook RW, Middlebrook B, Wilkinson J, Covington KR, Oelschlager K, Monzon FA, et al. Analytic validity of DecisionDx-Melanoma, a gene expression profile test for determining metastatic risk in melanoma patients. Diagn Pathol. 2018 Feb 13;13(1):13.

17. Teutsch SM, Bradley LA, Palomaki GE, Haddow JE, Piper M, Calonge N, et al. The Evaluation of Genomic Applications in Practice and Prevention (EGAPP) Initiative: methods of the EGAPP Working Group. Genetics in medicine: official journal of the American College of Medical Genetics. 2009 Jan;11(1):3-14.

18. New York State Department of Health. Clinical laboratory standards of practice. Albany, NY. 2021 May 5. Available: https://www.wadsworth.org/sites/default/files/WebDoc/EFFECTIVE_GeneralSystems_May2021_FINAL.pdf

\section{Tables}

Table 1. Inter-assay summary

Table 2. Intra-assay summary

Table 1. Inter-assay summary data for replicates 1 and 2 vs 3 and 4 were used for the evaluation of Class call concordance. 30 FFPE available samples were run in duplicate, for a total of 4 replicates, over two days by two different technologists and using two different machines. The individual sample class call averages of the replicates are shown.

Table 2. Intra-assay summary data for replicates 1 and 2 vs 3 and 4 were used for the evaluation of Class call concordance. 46 FFPE available samples were run in duplicate, for a total of 4 replicates, on the same day by the same technologist. The individual sample class call averages of the replicates are shown. 


\begin{tabular}{|c|c|c|c|c|c|c|c|}
\hline \multicolumn{4}{|c|}{ Avg Class Call for Replicates } & \multicolumn{4}{|c|}{ Avg Class Call for Replicates } \\
\hline Sample & $1 \& 2$ & $3 \& 4$ & Concordant & Sample & $1 \& 2$ & $3 \& 4$ & Concordant \\
\hline 1 & Class 1 & Class 1 & Yes & 1 & Class 1 & Class 1 & Yes \\
\hline 2 & Class 1 & Class 1 & Yes & 2 & Class 1 & Class 1 & Yes \\
\hline 3 & Class 2A & Class 2A & Yes & 3 & Class 1 & Class 1 & Yes \\
\hline 4 & Class 1 & Class 1 & Yes & 4 & Class 1 & Class 1 & Yes \\
\hline 5 & Class 1 & Class 1 & Yes & 5 & Class 2A & Class 2A & Yes \\
\hline 6 & Class 1 & Class 1 & Yes & 6 & Class 1 & Class 1 & Yes \\
\hline 7 & Class 1 & Class 1 & Yes & 7 & Class 1 & Class 1 & Yes \\
\hline 8 & Class 2A & Class 2A & Yes & 8 & Class 2A & Class 2A & Yes \\
\hline 9 & Class 1 & Class 1 & Yes & 9 & Class 1 & Class 2A & $\mathrm{No}^{*}$ \\
\hline 10 & Class 1 & Class 1 & Yes & 10 & Class 1 & Class 1 & Yes \\
\hline 11 & Class 1 & Class 1 & Yes & 11 & Class 1 & Class 1 & Yes \\
\hline 12 & Class 1 & Class 1 & Yes & 12 & Class 1 & Class 1 & Yes \\
\hline 13 & Class 1 & Class 1 & Yes & 13 & Class 1 & Class 1 & Yes \\
\hline 14 & Class 1 & Class 1 & Yes & 14 & Class 1 & Class 1 & Yes \\
\hline 15 & Class 2A & Class 1 & $\mathrm{No}^{*}$ & 15 & Class 1 & Class 1 & Yes \\
\hline 16 & Class 1 & Class 1 & Yes & 16 & Class 2A & Class 2A & Yes \\
\hline 17 & Class 1 & Class 1 & Yes & 17 & Class 1 & Class 1 & Yes \\
\hline 18 & Class 1 & Class 1 & Yes & 18 & Class 1 & Class 1 & Yes \\
\hline 19 & Class 2A & Class 2A & Yes & 19 & Class 2A & Class 2A & Yes \\
\hline 20 & Class 1 & Class 1 & Yes & & & & \\
\hline 21 & Class 2A & Class 2A & Yes & 20 & Class 2A & Class 2A & Yes \\
\hline 22 & Class 1 & Class 1 & Yes & 21 & Class 1 & Class 1 & Yes \\
\hline 23 & Class2B & Class2B & Yes & 22 & Class 1 & Class 1 & Yes \\
\hline 24 & Class 2A & Class2B & $\mathrm{No}^{*}$ & 23 & Class 2A & Class 2A & Yes \\
\hline 25 & Class 2A & Class 2A & Yes & 24 & Class 1 & Class 1 & Yes \\
\hline 26 & Class2B & Class2B & Yes & 25 & Class 1 & Class 1 & Yes \\
\hline 27 & Class 1 & Class 1 & Yes & 26 & Class 1 & Class 1 & Yes \\
\hline 28 & Class 2A & Class 2A & Yes & 27 & Class 1 & Class 1 & Yes \\
\hline 29 & Class2B & Class2B & Yes & 28 & Class 2A & Class 2A & Yes \\
\hline 30 & Class2B & Class 2A & No** & 29 & Class 1 & Class 1 & Yes \\
\hline *Not con & ordant & & & 30 & Class 1 & Class 1 & Yes \\
\hline
\end{tabular}




\begin{tabular}{|c|c|c|c|c|}
\hline **Excluded, dilution error & 31 & Class 1 & Class 1 & Yes \\
\hline \multirow{16}{*}{$\begin{array}{l}\text { Table } 3 \text {. Summary data for sample stability, longevity \& } \\
\text { reagent reproducibility. } \mathrm{RT}=\text { reverse transcription, } \mathrm{OA}=\text { open } \\
\text { array, } \mathrm{MM}=\text { master mix }\end{array}$} & 32 & Class 1 & Class 1 & Yes \\
\hline & 33 & Class 1 & Class 1 & Yes \\
\hline & 34 & Class 1 & Class 1 & Yes \\
\hline & 35 & Class 1 & Class 1 & Yes \\
\hline & 36 & Class 1 & Class 1 & Yes \\
\hline & 37 & Class 2A & Class 2A & Yes \\
\hline & 38 & Class 1 & Class 1 & Yes \\
\hline & 39 & Class2B & Class2B & Yes \\
\hline & 40 & Class2B & Class2B & Yes \\
\hline & 41 & Class 2A & Class 2A & Yes \\
\hline & 42 & Class 2A & Class 2A & Yes \\
\hline & 43 & Class2B & Class2B & Yes \\
\hline & 44 & Class 1 & Class 1 & Yes \\
\hline & 45 & Class 2A & Class 2A & Yes \\
\hline & 46 & Class2B & Class2B & Yes \\
\hline & \multicolumn{4}{|c|}{ *Not concordant } \\
\hline
\end{tabular}

\begin{tabular}{|lllc|}
\hline Additional Characteristics & Sample & $\begin{array}{l}\text { Overall Class Call } \\
\text { Concordance }\end{array}$ & Acceptable \\
\hline Longevity, RNA Stability & $\mathrm{n}=23$ & $96 \%(22 / 23)$ & $\geq 90 \%$ \\
\hline cDNA stability & $\mathrm{n}=15$ RT hold & $100 \%(15 / 15)$ & $\geq 90 \%$ \\
\hline $\begin{array}{l}\text { Lot to Lot Reagents } \\
\text { Reproducibility }\end{array}$ & $\mathrm{n}=10$ Extraction & $90 \%(9 / 10)$ & $\geq 90 \%$ \\
\cline { 2 - 3 } & $\mathrm{n}=11$ RT Kit \& RNase & $91 \%(10 / 11)$ & $\geq 90 \%$ \\
\hline $\begin{array}{l}n=5 \text { Pooled Assay \& Pre- } \\
\text { amplification MM }\end{array}$ & $100 \%(5 / 5)$ & $\geq 90 \%$ \\
\hline
\end{tabular}

\section{Figures}




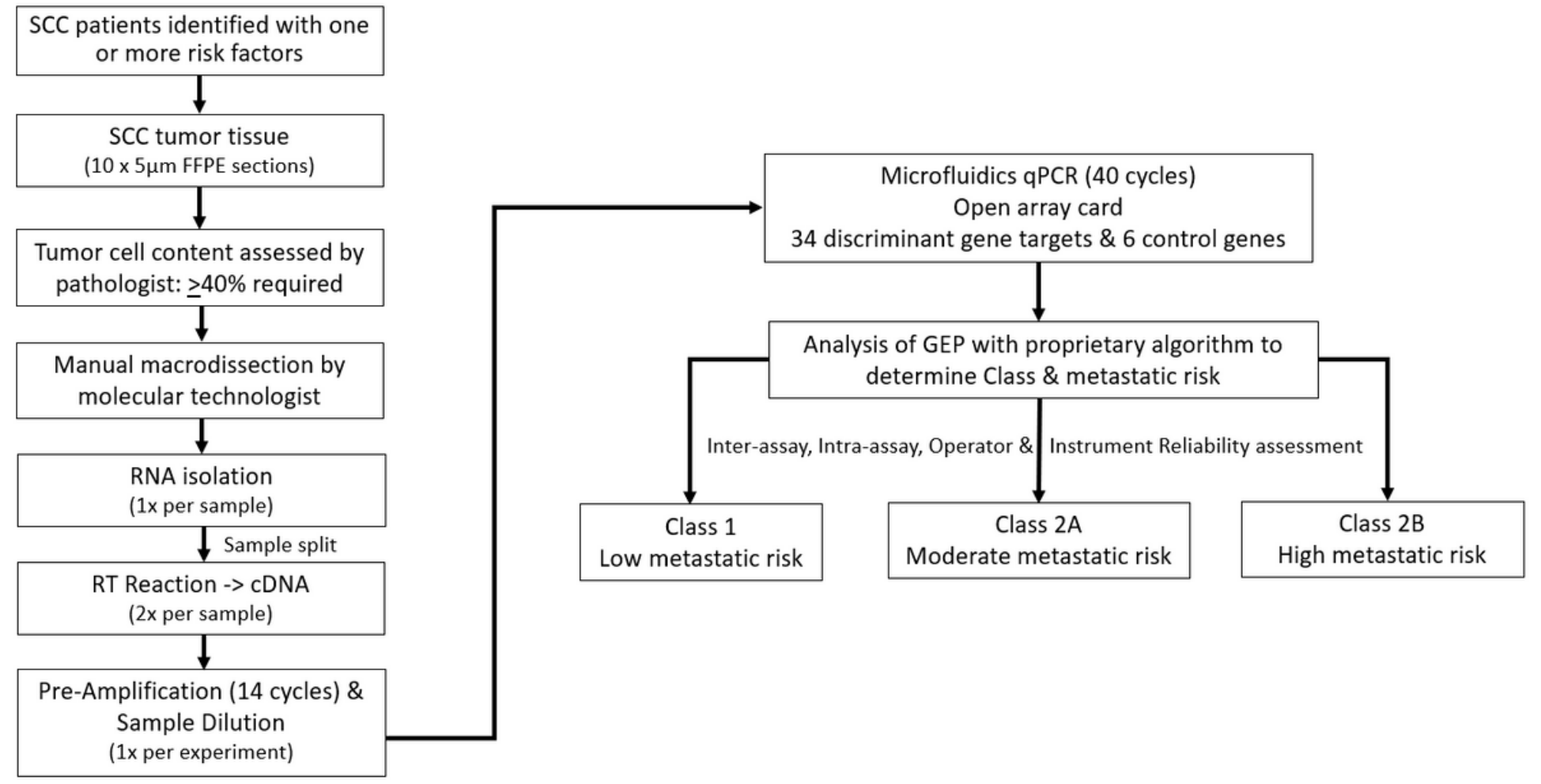

\section{Figure 1}

Workflow schematic of the DecisionDx-SCC test describing the steps in the performance of the test and presenting the corresponding reliability analyses. 
A)

Signature 1 RNA serial dilution

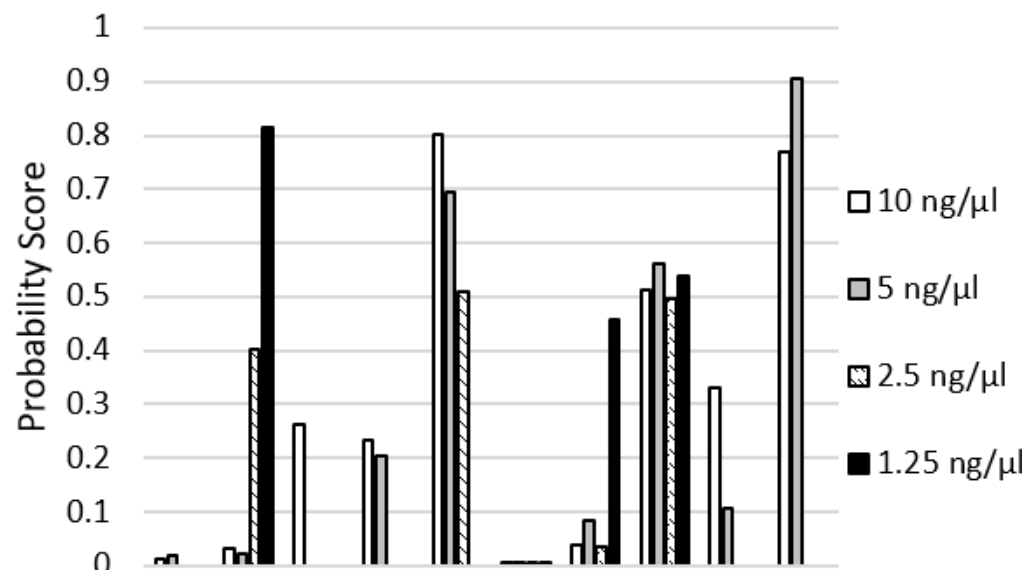

\begin{tabular}{|c|c|c|c|c|}
\hline \multicolumn{5}{|c|}{ Signature 1 RNA Serial Dilution } \\
\hline Sample & $10 \mathrm{ng} / \mu \mathrm{l}$ & $5 \mathrm{ng} / \mathrm{\mu l}$ & $2.5 \mathrm{ng} / \mu \mathrm{l}$ & $1.25 \mathrm{ng} / \mu \mathrm{l}$ \\
\hline 1 & 0.01 & 0.02 & MGF & MGF \\
\hline 2 & 0.03 & 0.02 & 0.40 & MGF \\
\hline 3 & 0.26 & MGF & MGF & MGF \\
\hline 4 & 0.23 & 0.20 & MGF & MGF \\
\hline 5 & 0.80 & 0.69 & 0.51 & MGF \\
\hline 6 & 0.00 & 0.00 & 0.00 & 0.00 \\
\hline 7 & 0.04 & 0.09 & 0.03 & 0.46 \\
\hline 8 & 0.51 & 0.56 & 0.50 & 0.54 \\
\hline 9 & 0.33 & 0.11 & MGF & MGF \\
\hline 10 & 0.77 & 0.91 & MGF & MGF \\
\hline
\end{tabular}

B)

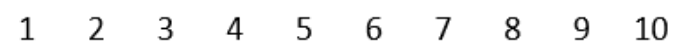

Sample Number

\section{Signature 2 RNA serial dilution}

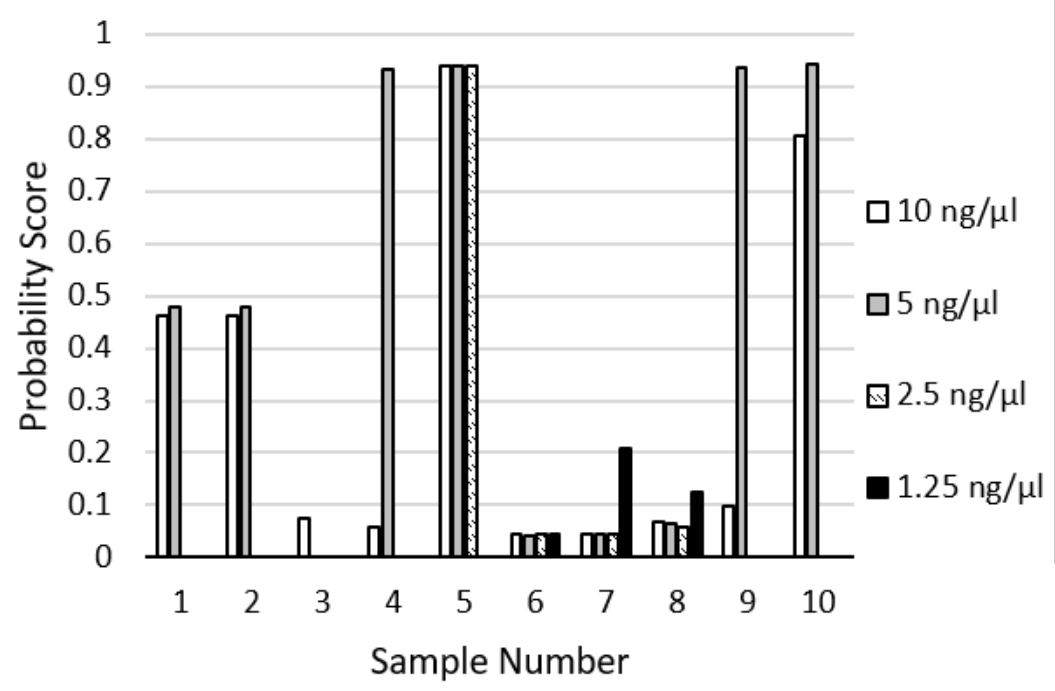

\begin{tabular}{|c|c|c|c|c|}
\hline \multicolumn{5}{|c|}{ Signature 2 RNA Serial Dilution } \\
\hline Sample & $10 \mathrm{ng} / \mu \mathrm{l}$ & $5 \mathrm{ng} / \mu \mathrm{l}$ & $2.5 \mathrm{ng} / \mu \mathrm{l}$ & $1.25 \mathrm{ng} / \mu \mathrm{l}$ \\
\hline 1 & 0.46 & 0.48 & MGF & MGF \\
\hline 2 & 0.46 & 0.48 & MGF & MGF \\
\hline 3 & 0.07 & MGF & MGF & MGF \\
\hline 4 & 0.06 & 0.93 & MGF & MGF \\
\hline 5 & 0.94 & 0.94 & 0.94 & MGF \\
\hline 6 & 0.04 & 0.04 & 0.05 & 0.04 \\
\hline 7 & 0.04 & 0.04 & 0.04 & 0.21 \\
\hline 8 & 0.07 & 0.06 & 0.06 & 0.12 \\
\hline 9 & 0.10 & 0.94 & MGF & MGF \\
\hline 10 & 0.80 & 0.94 & MGF & MGF \\
\hline
\end{tabular}

Figure 2

Determination of input RNA concentration using a serial dilution from 10-1.25 ng/ $\mu$, the probability scores of both A) Signature 1 and B) Signature 2 are shown for 10 FFPE samples. MGF-multiple gene failure 


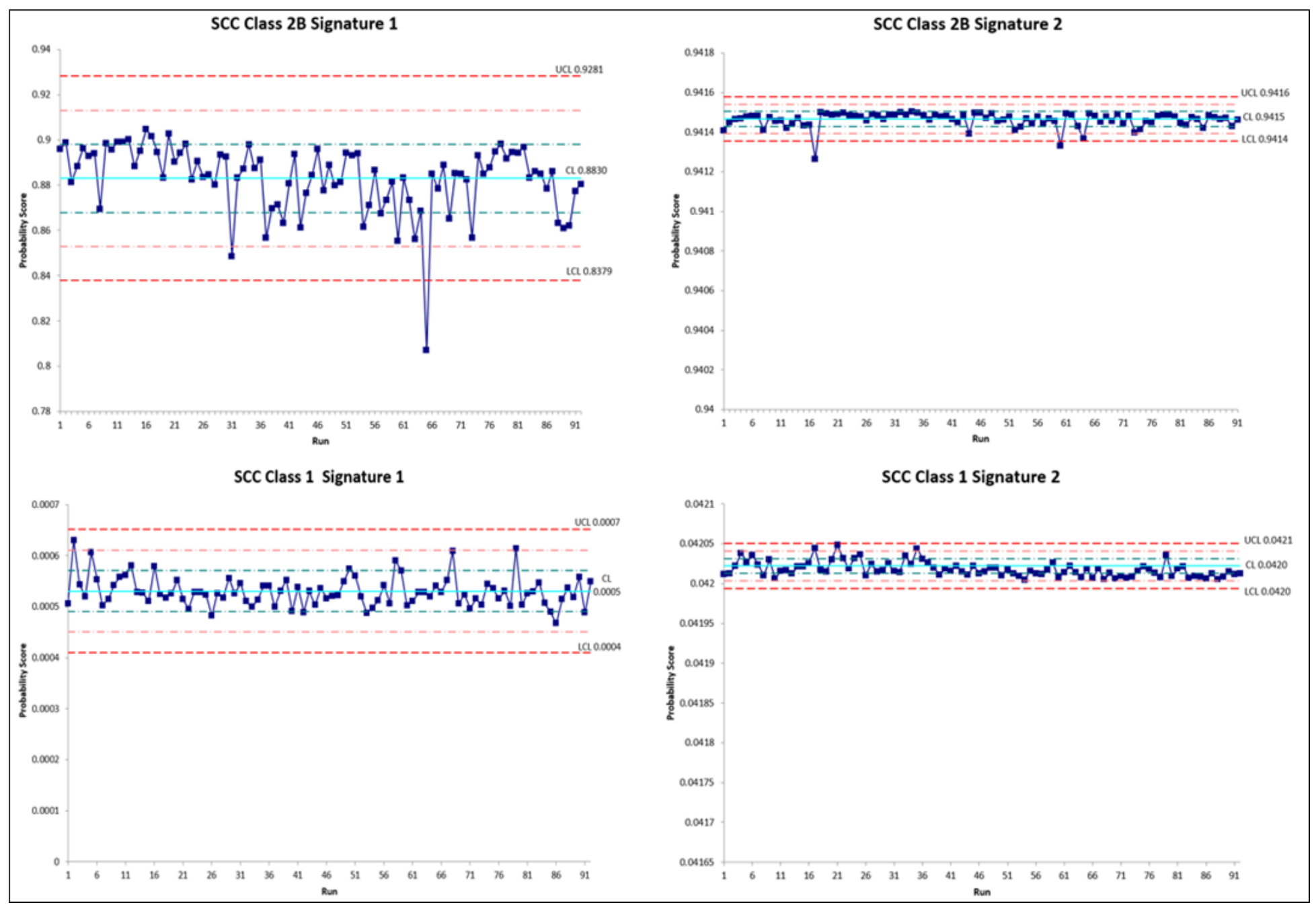

Figure 3

A Levey-Jennings graph depicts the positive control sample probability score stability and assay robustness across multiple runs. The reproducibility of the assay performance for a Class 1 and Class 2B positive control is shown. The mean is shown as the control limit (CL); +1SD is the dashed green line; +2SD is the dashed pink line; +3SD UCL (upper control limit) is the dashed red line; -3SD LCL (lower control limit) is the dashed red line. 


\section{DecisionDx-SCC Technical Success}

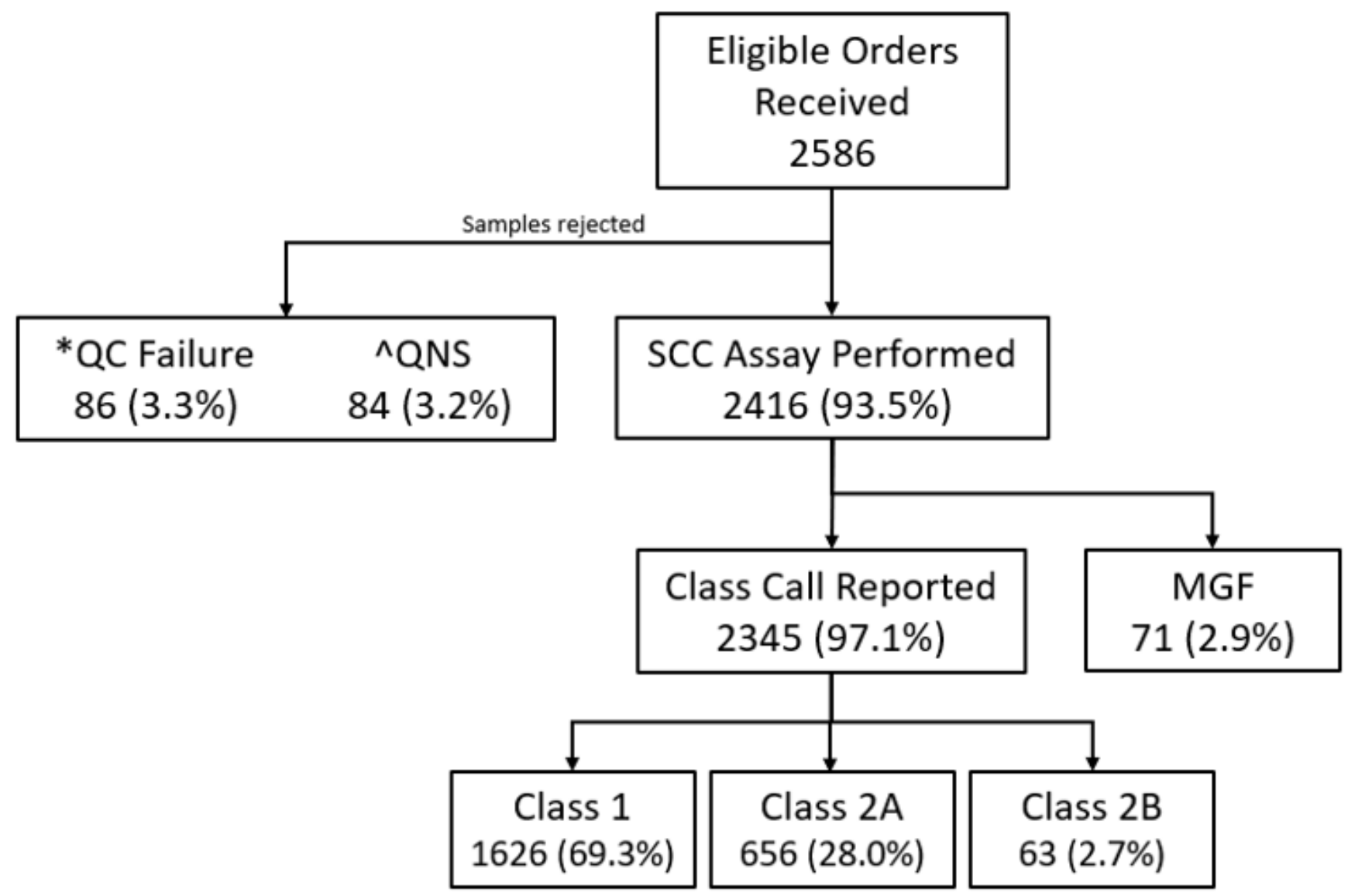

Figure 4

Technical experience of the DecisionDx-SCC test for orders submitted from September 1, 2020 - July 31, 2021. *QC failure = quality control failure $(<40 \%$ tumor content $) ;{ }^{\wedge} \mathrm{QNS}=$ quantity not sufficient $(\mathrm{RNA}<5.0 \mathrm{ng} / \mu \mathrm{l})$ 